\title{
Spectroscopic study of chemical phase separation in zirconium silicate alloys
}

\author{
G. B. Rayner, Jr., ${ }^{\text {a) }}$ D. Kang, and G. Lucovsky \\ Department of Physics, North Carolina State University, Raleigh, North Carolina 27695-8202
}

(Received 25 March 2003; accepted 30 May 2003; published 5 August 2003)

\begin{abstract}
This article presents a comprehensive spectroscopic study of chemical phase separation in zirconium silicate alloys, $\left(\mathrm{ZrO}_{2}\right)_{x}\left(\mathrm{SiO}_{2}\right)_{1-x}$, using Fourier transform infrared spectroscopy, x-ray photoelectron spectroscopy, extended x-ray absorption fine structure spectroscopy, and near edge $\mathrm{x}$-ray absorption spectroscopy. These measurements are complemented by measurements of x-ray diffraction and high resolution transmission electronic microscopy imaging. This combination has been applied to $\mathrm{Zr}$ silicate alloys, providing the first comprehensive comparisons of the relative sensitivities of these spectroscopic techniques applied to micro- and nanoscale chemical phase separation of high- $k$ dielectric alloys. (C) 2003 American Vacuum Society.
\end{abstract}

[DOI: 10.1116/1.1593646]

\section{INTRODUCTION}

One of the more important limitations for the integration of transition metal silicate alloys such as $\left(\mathrm{ZrO}_{2}\right)_{x}\left(\mathrm{SiO}_{2}\right)_{1-x}$ and $\left(\mathrm{HfO}_{2}\right)_{x}\left(\mathrm{SiO}_{2}\right)_{1-x}$ as gate dielectrics into advanced $\mathrm{Si}$ devices is a chemical phase separation of these pseudobinary alloys into $\mathrm{SiO}_{2}$ and transition metal oxides, $\mathrm{ZrO}_{2}$ for $\mathrm{Zr}$ silicate alloys, and $\mathrm{HfO}_{2}$ for $\mathrm{Hf}$ silicate alloys. ${ }^{1-3}$ The studies of this article are important for device processing, since phase separation results in significant decreases in effective dielectric constants, reducing the gate capacitance required for aggressive device scaling. This separation occurs in the same regime of temperatures, $\sim 900^{\circ} \mathrm{C}$, required for integration of deposited dielectrics into device fabrication processing. ${ }^{4,5}$ As an example, chemical phase separation occurs in the $1000^{\circ} \mathrm{C}$ temperature range required for dopant activation in source, drain, and polycrystalline gate electrodes in field effect transistors (FETs) employing conventional processing protocols. It is therefore important to identify spectroscopic approaches that cannot only identify chemical phase separation accompanied by crystallization detectable by conventional diffraction techniques such as $\mathrm{x}$-ray diffraction (XRD), but also to detect chemical phase separation that occurs with amorphous, or nanocrystalline phases too small for detection by conventional diffraction methods.

This article presents a comprehensive spectroscopic study of chemical phase separation using Fourier transform infrared spectroscopy (FTIR), x-ray photoelectron spectroscopy (XPS), x-ray absorption spectroscopy (XAS), ${ }^{6,7}$ including extended x-ray absorption fine structure spectroscopy (EXAFS), and near edge XAS (NEXAS). These measurements are complemented by measurements of x-ray diffraction (XRD) and high resolution transmission electronic microscopy (HRTEM) imaging. This combination has been applied to $\mathrm{Zr}$ silicate alloys, and provides the first comprehensive comparisons of the relative sensitivities of these techniques

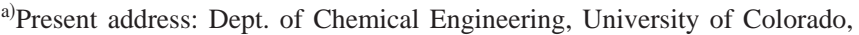
Boulder, CO 80309; electronic mail: gerry_lucovsky@ncsu.edu
}

applied to nanoscale chemical phase separation of dielectric alloys. The techniques used in this study can also be applied to chemical phase separation in other silicate alloy systems including Hf silicate alloys as in Ref. 3.

\section{EXPERIMENTAL PROCEDURES}

Rutherford backscattering spectroscopy (RBS), XPS, Auger electron spectroscopy (AES) and XAS measurements utilized films approximately $20-50 \mathrm{~nm}$ thick deposited onto $\mathrm{Si}(100)$ substrates at $300{ }^{\circ} \mathrm{C}$ by a remote plasma process described in detail elsewhere. ${ }^{2}$ Films greater than approximately $150 \mathrm{~nm}$ thick were deposited: (i) onto $\mathrm{Si}(100)$ substrates for FTIR and XRD and (ii) onto fused silica substrates for EXAFS and NEXAS measurements. In summary, the respective $\mathrm{Si}$ and $\mathrm{Zr}$ source gases, $2 \% \mathrm{SiH}_{4}$ in $\mathrm{He}$, and $\mathrm{Zr}$ (IV) $t$-butoxide, $\mathrm{Zr}\left[\mathrm{OC}\left(\mathrm{CH}_{3}\right)_{3}\right]_{4}$, were delivered directly into the substrate downstream region of a remote plasma reactor through two different shower-head injectors. The reaction was driven by active oxygen atom species produced in the remote plasma generation region of the reactor and transported downstream by the gas flow dynamics. The Zr:Si ratio in the deposited films was determined by the relative flow rates of the respective $\mathrm{Zr}$ and $\mathrm{Si}$ source gases. An $\mathrm{He} / \mathrm{O}_{2}$ (20:1) mixture was subjected to remote plasma excitation, 15 $\mathrm{W}$ at $13.56 \mathrm{MHz}$, and used to initiate the remote plasma enhanced chemical vapor deposition (RPECVD) process. Substrates were treated in a $\mathrm{H}_{2} \mathrm{O} / \mathrm{HF}(100: 1)$ solution prior to film deposition to remove the superficial native oxide. Prior to the $\mathrm{Zr}$ silicate alloy deposition, an $a-\mathrm{SiO}_{2}$ layer approximately $3 \mathrm{~nm}$ thick was deposited on the Si substrate by RPECVD to provide a chemical buffer layer between the plasma-deposited $\mathrm{Zr}$ silicate alloys and the Si substrate. The purpose of this buffer layer was: (i) to suppress $\mathrm{Zr}$ source gas reactions with the Si substrate during film deposition and (ii) to prevent reactions between the alloy and the $\mathrm{Si}$ substrate during postdeposition annealing. The alloy composition of the bulk films, reported as the $\mathrm{Zr}: \mathrm{Si}: \mathrm{O}$ ratio, was determined by RBS. RBS results indicated that the $\left(\mathrm{ZrO}_{2}\right)_{x}\left(\mathrm{SiO}_{2}\right)_{1-x}$ alloy films were homogeneous, and fully oxidized with an 
uncertainty in composition, $\delta x= \pm 0.03 .^{1,2}$ These results were used to calibrate on-line AES results where a linear dependence was demonstrated between the ratio of the derivative spectrum peak-to-peak heights for $\mathrm{Zr}_{M N N(M V V)}$ and $\mathrm{O}_{K V V(K L L)}$ features and alloy composition as determined by RBS. Films were annealed ex situ in an inert Ar ambient for 1 min utilizing an AG minipulse 310 rapid thermal annealing (RTA) apparatus with an uncertainty in annealing temperature of $\pm 15{ }^{\circ} \mathrm{C}$.

FTIR absorption measurements, in the mid-IR $\left(4000-400 \mathrm{~cm}^{-1}\right)$ and far-IR $\left(700-50 \mathrm{~cm}^{-1}\right)$, were performed utilizing a Nicolet Magna-FTIR 750 spectrometer. The spectrometer was continuously purged with dry $\mathrm{N}_{2}$ delivered from a liquid $\mathrm{N}_{2}$ source to minimize absorption from IR active species present in the atmosphere, e.g., $\mathrm{H}_{2} \mathrm{O}$ and $\mathrm{CO}_{2}$. The spectrometer utilizes a $\mathrm{He} / \mathrm{Ne}$ laser for optical bench alignment which was performed prior to all data collection runs. The mid-IR measurements utilized a deuterated tri-glycine sulfate (DTGS) detector with a $\mathrm{KBr}$ window, and a KBr beam splitter. The far-IR measurements a DTGS detector with a polyethylene window and a Si substrate beam splitter.

XRD measurements were made using a Bruker $\mathrm{x}$-ray diffractometer with a beryllium area detector centered at $2 \theta$ positions of $25^{\circ}$ and $50^{\circ}$. XPS measurements of $\mathrm{O} 1 \mathrm{~s}, \mathrm{C} 1 \mathrm{~s}$, $\mathrm{Zr} 3 d$, and Si $2 p$ core levels were made using a Riber LAS3000 spectrometer with nonmonochromatic $\mathrm{Mg} K \alpha$ radiation $(1253.6 \mathrm{eV})$ and a pass energy of $20 \mathrm{eV}$. The system base pressure for XPS measurements was $3 \times 10^{-10}$ Torr. Data were corrected for charging effects using the $\mathrm{C} 1 s$ peak at $284.6 \mathrm{eV}$ from adventitious carbon contamination on the film surface. The repeatability of measuring peak spectral positions was found to be $<0.2 \mathrm{eV}$. The as-deposited films were also characterized on-line by AES using a Phi system at a base pressure of $8 \times 10^{-10}$ Torr. The Auger process was initiated by a $3 \mathrm{keV} e$ beam which was defocused to prevent damage to the film structure. $\mathrm{O}_{K V V}$ and $\mathrm{Zr}_{M V V}$ transitions were measured as a function of film composition and the repeatability of peak kinetic energy determinations was $<0.4 \mathrm{eV}$

EXAFS and NEXAS measurements were made at the National Synchrotron Light Source at Brookhaven National Laboratory. ${ }^{6}$ Absorption spectra for the $\mathrm{O} K_{1}$ edge NEXAFS were recorded by measuring the photon energy dependence of primary photoelectron yield, and absorption data for the EXAFS and NEXAS studies using the $\mathrm{Zr} K_{1}$ edge were obtained by monitoring $\mathrm{X}$-ray fluorescence.

\section{EXPERIMENTAL RESULTS}

FTIR results are shown in Figs. 1(a) -1 (c) for the mid-IR spectral range from 400 to $1600 \mathrm{~cm}^{-1}$. As a point of reference, this spectral range includes the $\mathrm{Si}-\mathrm{O}-\mathrm{Si}$ asymmetric stretching vibration between 900 and $1300 \mathrm{~cm}^{-1}$, the $\mathrm{Si}-$ $\mathrm{O}-\mathrm{Si}$ symmetric stretching (or bending) vibration centered at about $810 \mathrm{~cm}^{-1}$, and the $\mathrm{Si}-\mathrm{O}-\mathrm{Si}$ out-of-plane rocking vibration centered at about $450 \mathrm{~cm}^{-1}$, all for noncrystalline $\mathrm{SiO}_{2} \cdot{ }^{8,9}$ Figure 2 includes a FTIR spectrum over a wider
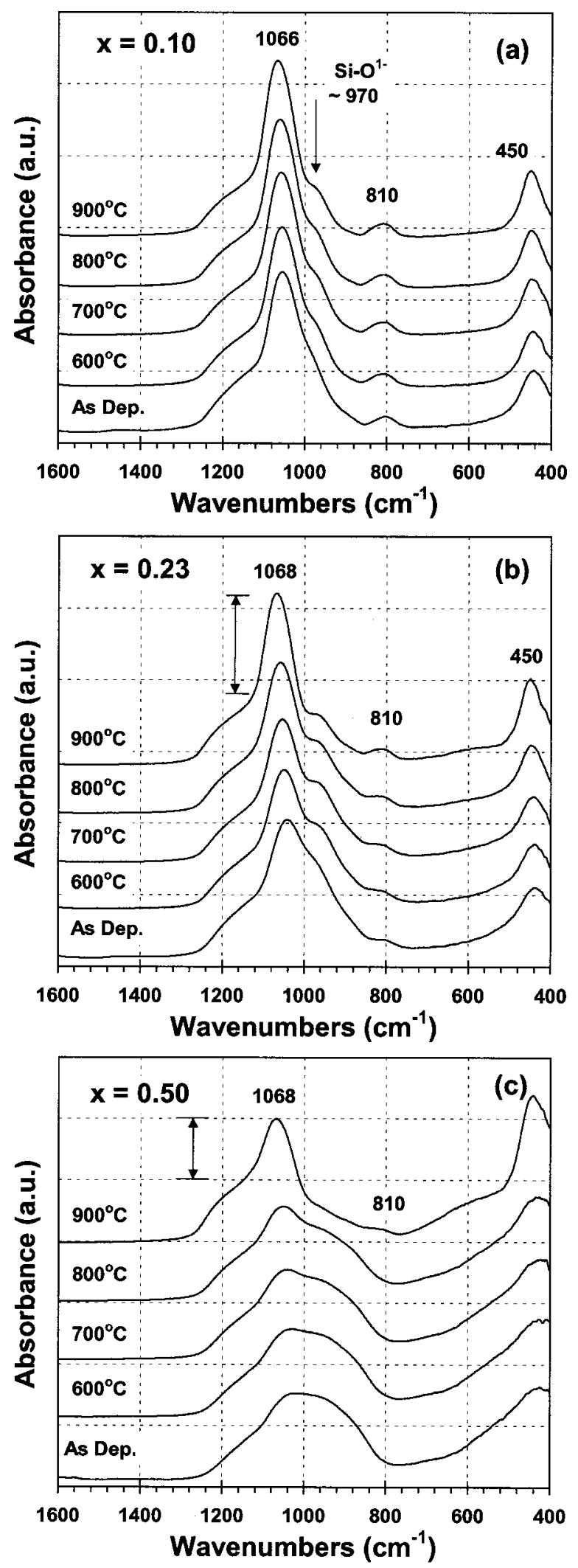

FIG. 1. Infrared absorbance vs wave number $\left(\mathrm{cm}^{-1}\right)$ for alloy samples with: (a) $x=0.10$, (b) $x=0.23$, and (c) $x=0.5$. Spectra are plotted from bottom to top as a function of temperature, as deposited, and annealed in Ar for $1 \mathrm{~min}$ at $600,700,800$, and $900{ }^{\circ} \mathrm{C}$. 


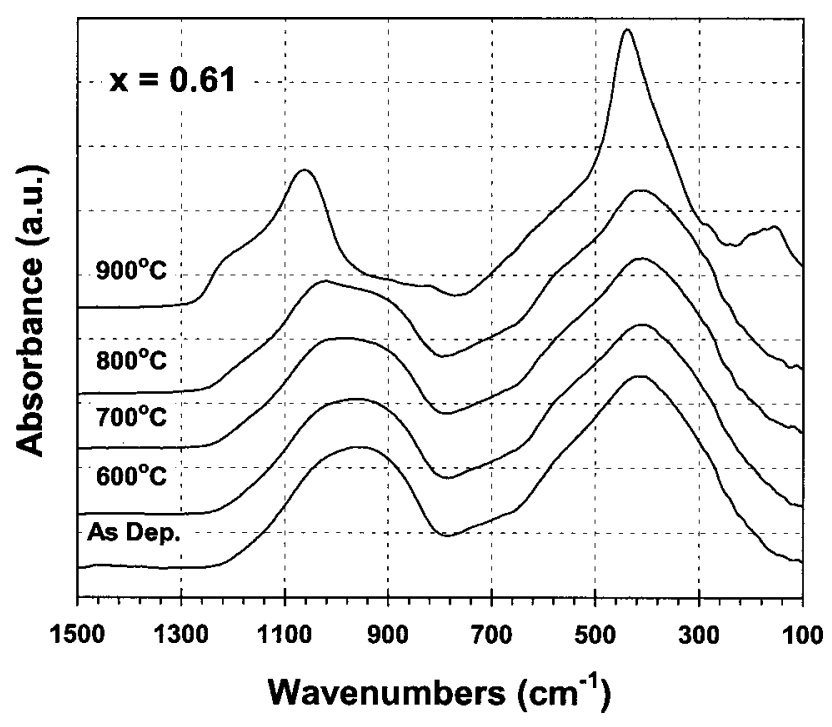

FIG. 2. Infrared absorbance vs wave number $\left(\mathrm{cm}^{-1}\right)$ for alloy samples with $x=0.61$. Spectra are plotted from bottom to top as a function of temperature, as deposited, and annealed in Ar for 1 min at 600, 700, 800, and $900{ }^{\circ} \mathrm{C}$.

spectral range $\left(100-1500 \mathrm{~cm}^{-1}\right)$ for an alloy with $x=0.61$. Figure 3 displays the spectrum from 200 to $1200 \mathrm{~cm}^{-1}$ for an as-deposited $\mathrm{ZrO}_{2}$ film. There are no changes in the spectral features of this film as function of postdeposition annealing to $900^{\circ} \mathrm{C}$, consistent with no detectable $\mathrm{OH}$ or $\mathrm{H}_{2} \mathrm{O}$ bands in the infrared spectrum. Our experience with high $\mathrm{OH}$ and/or $\mathrm{H}_{2} \mathrm{O}$ content $\mathrm{ZrO}_{2}$ or $\mathrm{HfO}_{2}$ films is that they are amorphous as-deposited, and then crystallize at temperatures of about $400-600^{\circ} \mathrm{C}$ as the $\mathrm{OH}$ and/or $\mathrm{H}_{2} \mathrm{O}$ leaves the film, or reacts with the $\mathrm{Si}$ substrate.

The changes in the $\mathrm{Zr}$ silicate spectra observed in Figs. 1 and 2 with respect to alloy composition in the as-deposited state are brought about by alloying with $\mathrm{ZrO}_{2}$, and the

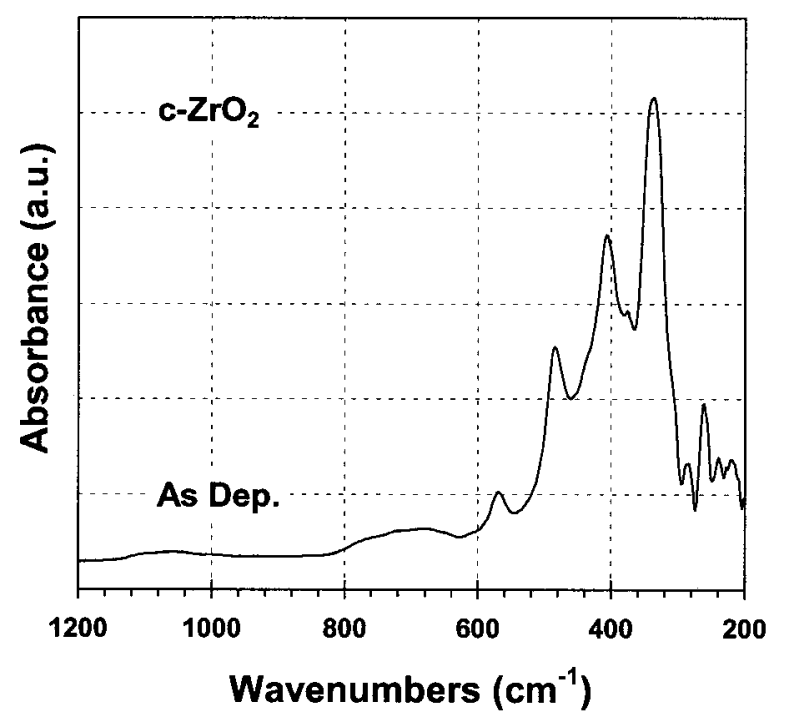

FIG. 3. Infrared absorbance vs wave number $\left(\mathrm{cm}^{-1}\right)$ for an as-deposited, crystalline $\mathrm{ZrO}_{2}$ thin film.
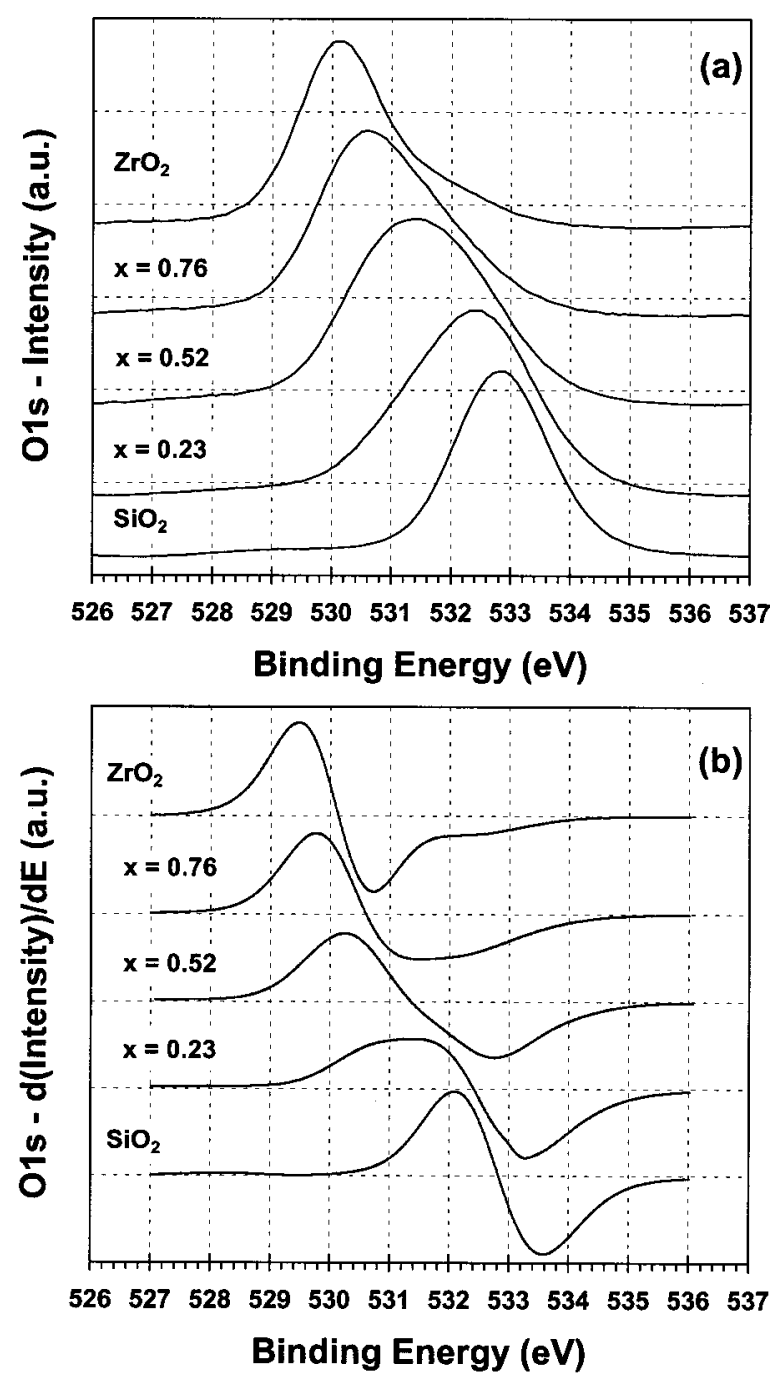

FIG. 4. X-ray photoelectron core level spectra: (a) O $1 s$ and (b) numerical derivative of $\mathrm{O} 1 \mathrm{~s}$. Each of these spectra is for as-deposited $\left(300{ }^{\circ} \mathrm{C}\right) \mathrm{Zr}$ silicate alloys with $x=0.00,0.23,0.62,0.78$, and 1.00 .

changes after annealing at $900^{\circ} \mathrm{C}$ will be shown to be associated with chemical phase separation with and without crystallization detectable by XRD.

XPS results are shown in Figs. 4-6. Figures 4(a) and 4(b) are, respectively, $\mathrm{O} 1 s$ core level and numerically differentiated spectra. The systematic changes in line shape in Figs. 4(a) and 4(b) have been interpreted in terms of changes in the oxygen atom coordination with alloy composition. ${ }^{2}$ In the range of alloy composition from $x=0.0$ to 0.5 , where $x$ $=0.5$ corresponds to the chemically ordered $\mathrm{ZrSiO}_{4}$ phase, the $\mathrm{O}$ atom coordination increases from two for $\mathrm{SiO}_{2}$ to three for $\mathrm{ZrSiO}_{4}$, while in the range from $x=0.5$ to 1.0 the coordination increases from three to four for $\mathrm{ZrO}_{2}{ }^{2}$

Figures 5(a) and 5(b) display XPS core level spectra, respectively, for the Si $2 p$ feature, and the $\mathrm{Zr} 3 d$ doublet. The weaker $\mathrm{Zr} 3 d$ doublet feature with the larger core level binding energy between approximately 184 and $186 \mathrm{eV}$ is the $\mathrm{Zr}$ $3 d_{3 / 2}$ component, and the stronger feature between 181 and $183 \mathrm{eV}$ is the $\mathrm{Zr} 3 d_{5 / 2}$ component. Figure 6 presents XPS O $1 s$ core level spectra for $\left(\mathrm{ZrO}_{2}\right)_{x}\left(\mathrm{SiO}_{2}\right)_{1-x}$ alloys with com- 


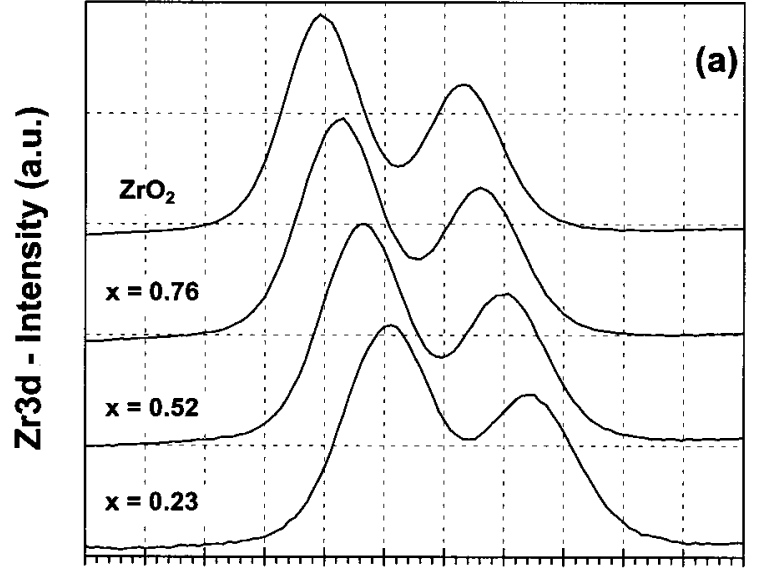

$\begin{array}{llllllllllll}178 & 179 & 180 & 181 & 182 & 183 & 184 & 185 & 186 & 187 & 188 & 189\end{array}$ Binding Energy (eV)

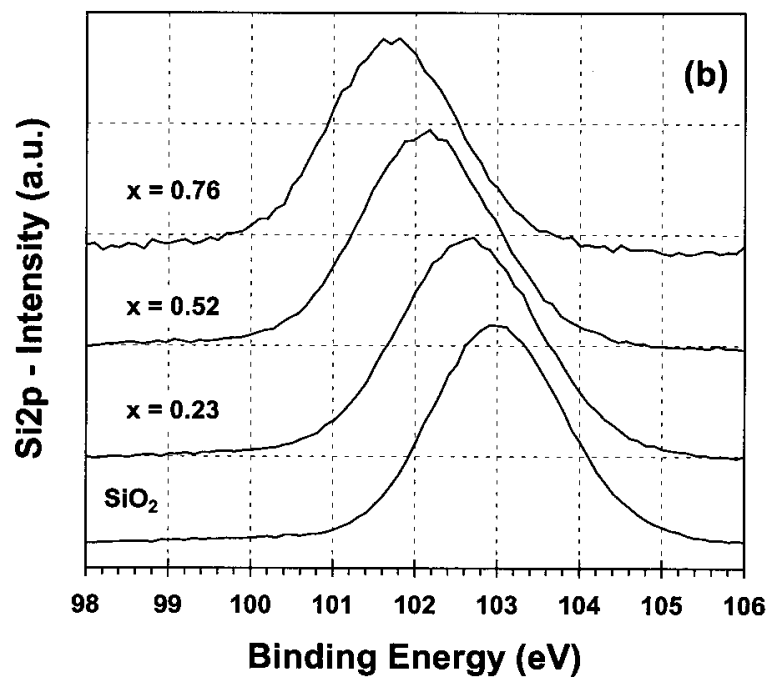

FIG. 5. X-ray photoelectron core level spectra for as-deposited $\left(300^{\circ} \mathrm{C}\right) \mathrm{Zr}$ silicate alloy films: (a) $\mathrm{Zr} 3 d$ for $x=0.23,0.62,0.78$, and 1.00 and (b) Si $2 p$ for $0.00,0.23,0.62$, and 0.78 .

positions, $x=0.35,0.45,0.60$. The plots in Fig. 6(a) are for samples annealed in $\mathrm{Ar}$ at $900^{\circ} \mathrm{C}$ for $60 \mathrm{~s}$ and those in Fig. 6(b) are the corresponding first derivatives. These are to be compared, respectively, with spectra in Figs. 4(a) and 4(b), which are for as-deposited films with compositions spanning the same range as those in Figs. 6(a) and 6(b). The spectra in Figs. 4(a) and 4(b) indicate asymmetric line shapes, whereas those in Figs. 6(a) and 6(b) clearly indicate two discrete and separated spectral components.

Oxygen atom $K_{1}$ NEXAFS spectra for transitions originating in the $\mathrm{O} 1 s$ state are displayed in Figs. 7(a) and 7(b) for $\mathrm{Zr}$ silicate alloys (a) as-deposited and (b) after a $900{ }^{\circ} \mathrm{C}$ rapid thermal anneal. ${ }^{6,7}$ The $\mathrm{Zr} 4 d^{*}$ features, marked in Fig. 7 (a), sharpen up after the annealing, and the $\mathrm{Zr} 5 s^{*}$ band between 540 and $550 \mathrm{eV}$ develops structure indicative of the crystalline state. It will be shown in Sec. IV that the spectra in Fig. 7(b) are for alloys that have undergone a chemical phase separation associated with the formation of either nanocrystalline $\mathrm{ZrO}_{2}$ for $x=0.35$ and 0.45 , or a larger scale crystalline component for $x=0.6$.
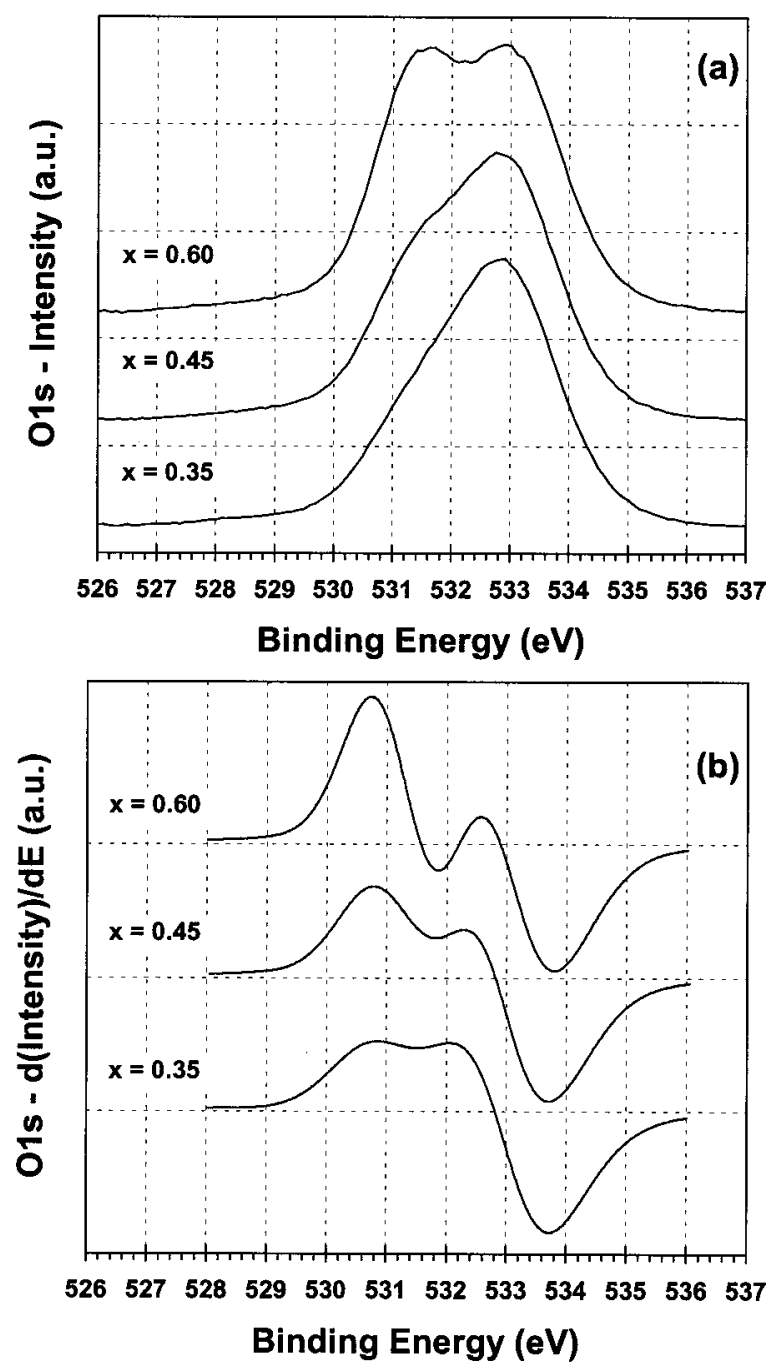

FIG. 6. X-ray photoelectron core level (a) O $1 s$ spectra of $\left(\mathrm{ZrO}_{2}\right)_{x}\left(\mathrm{SiO}_{2}\right)_{1-x}$ alloys with $x=0.35,0.45$, and 0.60 annealed in $\mathrm{Ar}$ at $900{ }^{\circ} \mathrm{C}$ for $60 \mathrm{~s}$ and (b) the corresponding derivative spectra.

Figures $8(a)$ and $8(b)$ present the results of EXAFS studies for compositions of $x=0.25$ and 0.55 , and are complemented in Figs. 9(a) and 9(b), which display NEXAS for the alloy with $x=0.55 .{ }^{10}$ Consider first the radial distribution functions (RDFs) obtained from the analysis of the EXAFS data. ${ }^{11}$ The as-deposited samples are essentially the same except for a narrowing of the $\mathrm{Zr}-\mathrm{O}$ peak and the reduction of a satellite feature at a slightly increased radius. There are more significant changes between these RDFs after the $900^{\circ} \mathrm{C}$ anneal. The most notable is the increase in relative strength of the peak labeled $\mathrm{Zr}-\mathrm{Zr}$, which corresponds to a second neighbor distance. Additional features, marked with arrows and due to more distant $\mathrm{Zr}-\mathrm{O}$ and $\mathrm{Zr}-\mathrm{Zr}$ coordination shells, are also stronger in the $x=0.55$ sample.

Figures 9(a) and 9(b) are NEXAS ${ }^{12}$ and the corresponding numerically differentiated NEXAS spectra, respectively, of an as-deposited and annealed alloy with $x=0.55$. By analogy with spectra in Fig. 7(a), the shoulder at $\sim 18.003 \mathrm{keV}$ in Fig. 9(a) and the peak at $\sim 18.000 \mathrm{keV}$ in Fig. 9(b) are assigned to transitions from the $\mathrm{Zr} 1 s$ state to $\mathrm{Zr} 4 d^{*}$ states, 

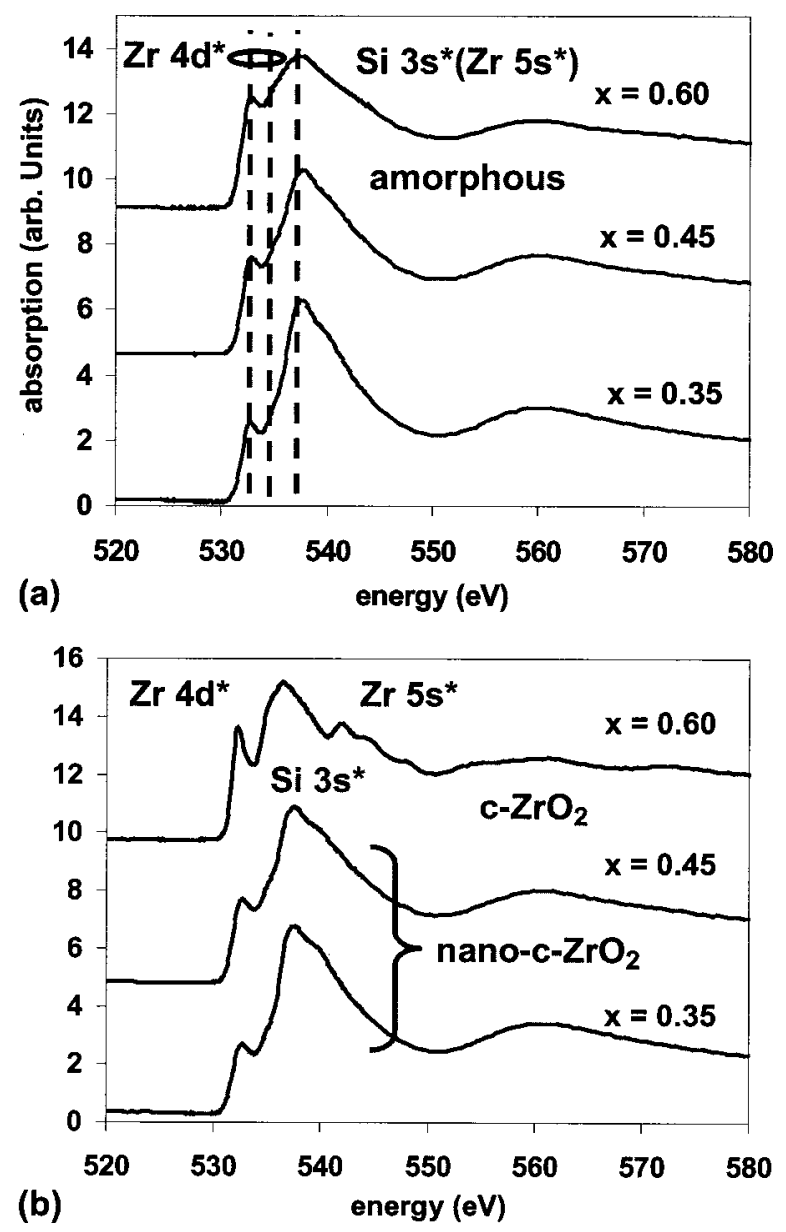

FIG. 7. O $K_{1}$ NEXAS for $\mathrm{Zr}$ silicate alloy with $x=0.35$, 0.45, and 0.60: (a) as deposited and (b) after a $900{ }^{\circ} \mathrm{C} 1 \mathrm{~min}$ anneal in Ar.

and the features at $\sim 18.015$ and $\sim 18.030 \mathrm{keV}$ in Fig. 9(a), and peak at $\sim 18.010 \mathrm{keV}$ in Fig. 9 (b) are assigned, respectively, to transitions to $\mathrm{Zr} 5 s^{*}$ states. ${ }^{7}$ FTIR indicates $\mathrm{SiO}_{2}$ and $\mathrm{ZrO}_{2}$ phases for $x>0.5$ following a $900{ }^{\circ} \mathrm{C}$ RTA and XRD reveals $c-\mathrm{ZrO}_{2}$ in a tetragonal phase. Therefore, the NEXAS for $x \sim 0.55$ sample following $900^{\circ} \mathrm{C}$ RTA corresponds mainly to the $\mathrm{Zr}$ atoms in the $\mathrm{ZrO}_{2}$ phase, i.e., $\mathrm{Zr}-\mathrm{Zr}$ second neighbor bonding. The spectroscopy results presented above are complemented by XRD data in Figs. 10(a) and 10(b), and high resolution transmission electronic microscopy imaging in Figs. 11(a) and 11(b). Consider first the as-deposited films in Figs. 10(a) and 10(b), where the primary difference is the strength of a broad noncrystalline feature that occurs about $2 \theta$ values of $26^{\circ}$ and $38^{\circ}$. This feature is stronger in the 0.5 alloy in Fig. 10(b) than in the 0.23 alloy in Fig. 10(a) and therefore must be assigned to a $\mathrm{Zr}$ bonding feature. The broad feature in Fig. 10(b) does not change for anneals up to $800^{\circ} \mathrm{C}$, but at $900{ }^{\circ} \mathrm{C}$, the XRD spectrum in Fig. 10(b) changes markedly and the peaks index as tetragonal $\mathrm{ZrO}_{2}$. In contrast, no crystalline features are detected in Fig. 10(a) after the $900^{\circ} \mathrm{C}$ anneal.

The HRTEM images in Figs. 11(a) and 11(b) are after a $900^{\circ} \mathrm{C}$ anneal, respectively, for alloys with compositions $x$
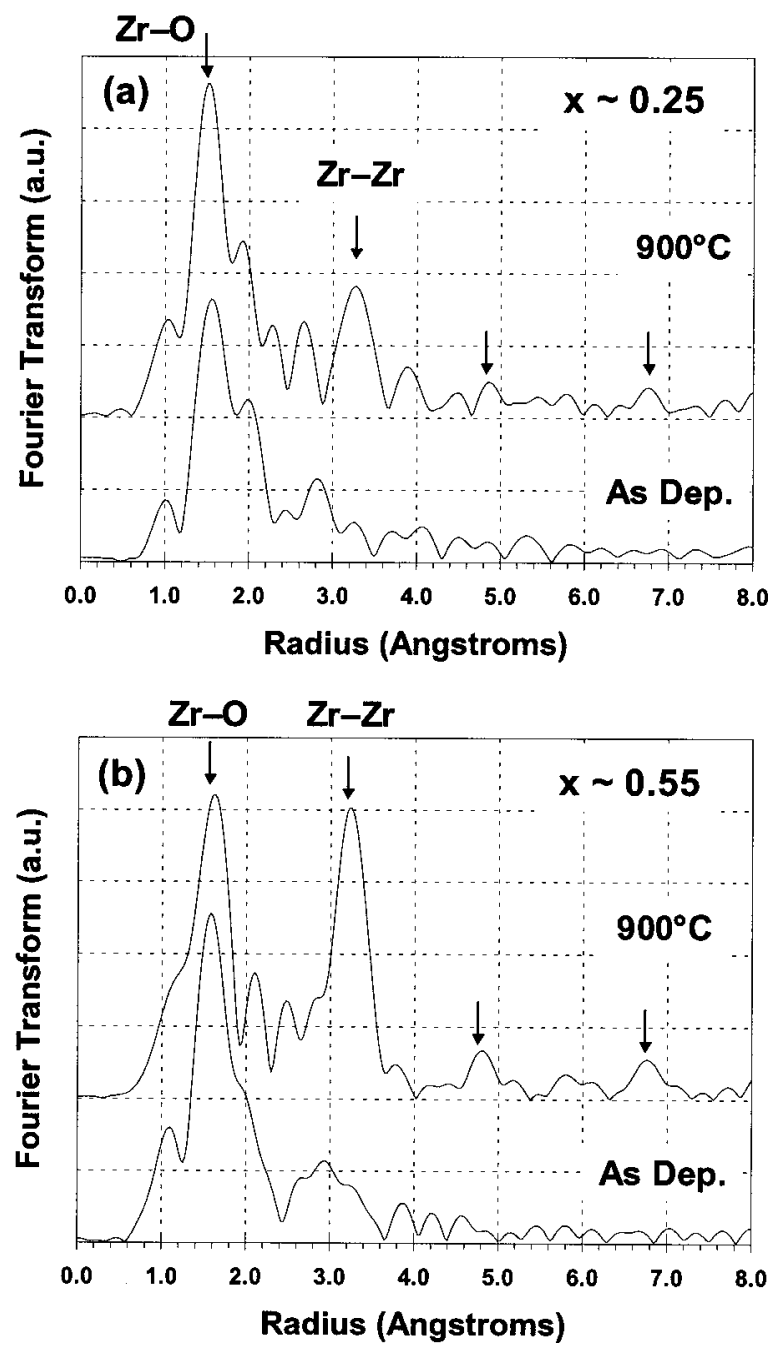

FIG. 8. Fourier transform radical distribution functions, obtained from EXAFS vs interatomic distance for two $\mathrm{Zr}$ silicate alloys with: (a) $x=0.25$ and (b) $x=0.55$. Transforms are for as-deposited and $900{ }^{\circ} \mathrm{C}$ annealed samples.

$=0.23$ and 0.5 . The $x=0.23$ micrograph displays darker regions, four of which are highlighted, separated by brighter regions. Based on differences in atomic weight, the dark regions are assumed to be $\mathrm{ZrO}_{2}$ (atomic weight=107.2 a.u.) or $\mathrm{ZrO}_{2}$ rich, and the lighter regions are assumed to $\mathrm{SiO}_{2}$ (atomic weight $=60.1$ a.u.) or $\mathrm{SiO}_{2}$ rich. Based on the spacing of lattice planes in the $\mathrm{Si}$ substrate, the dark regions are nanometer in scale, $\sim 3-5 \mathrm{~nm}$. The circled region in the upper right-hand region shows some parallel line structure indicative of increased long range order with respect to the other three highlighted regions; however, a comparison with the highlighted regions in Fig. 11(b) indicates that these parallel line structures are restricted to a smaller region, and that the lines in Fig. 11(a) are qualitatively different as well. These assignments in Fig. 11(a) with regard to the chemical constituents in dark and bright regions are consistent with the micrograph in Fig. 11(b) that shows the dark regions of Fig. 11(b) having parallel lines, indicative of lattice planes that are assigned to $\mathrm{ZrO}_{2}$. The crystallite size in the region circled in Fig. 11(b) is larger than about $10 \mathrm{~nm}$ in its longest 

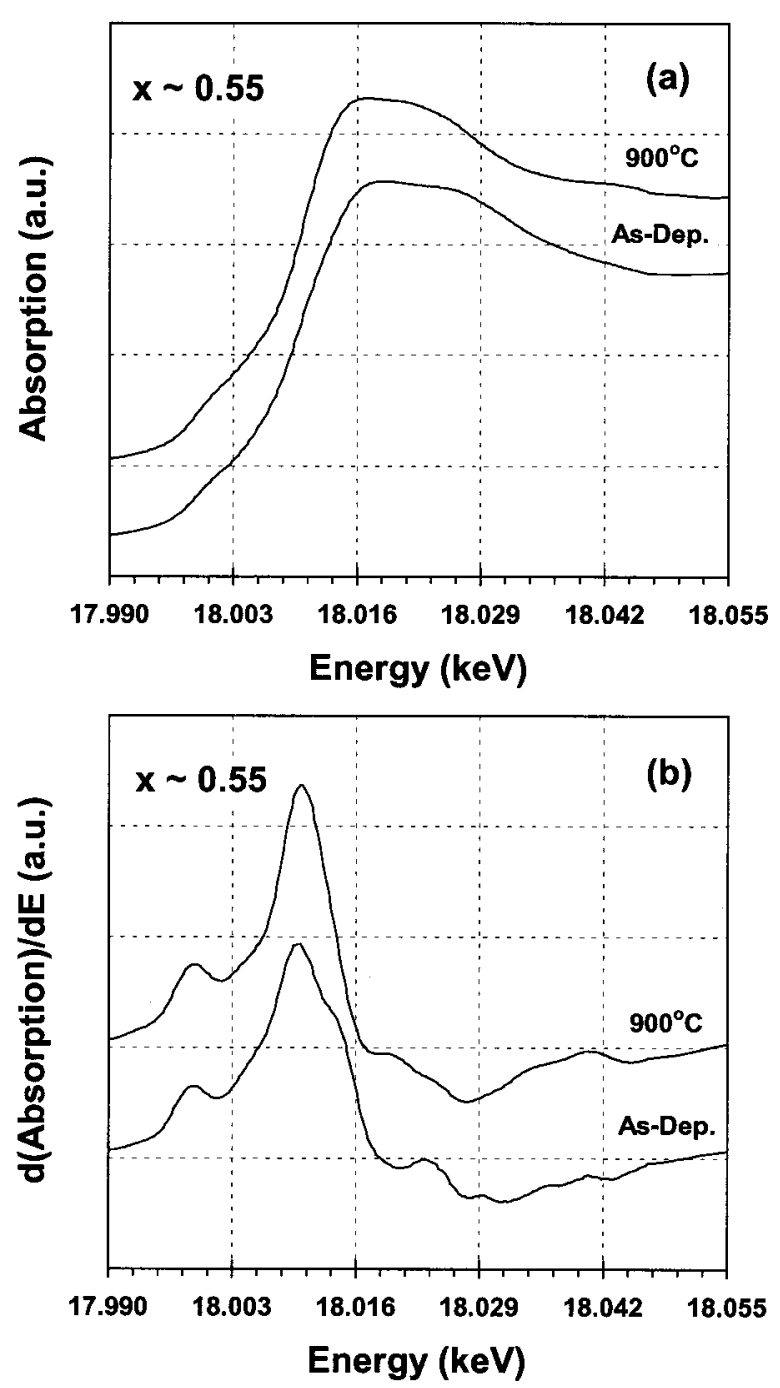

FIG. 9. NEXAFS for a $0.55 \mathrm{Zr}$ silicate alloys, displaying the absorption spectra, and the differentiated absorption spectra for as-deposited and $900^{\circ} \mathrm{C}$ annealed samples.

dimension and is about 2 to 3 times larger than the region highlighted in the upper left-hand corner of Fig. 11(a).

\section{DISCUSSION OF EXPERIMENTAL RESULTS}

Consider first the FTIR results in Figs. 1(a), 1(b), and 1 (c). The dominant features in the $x=0.10$ sample are clearly at frequencies close to the normal mode absorptions of low temperature, deposited noncrystalline $\mathrm{SiO}_{2}$ thin films. Of particular interest in these films is the shoulder at $970 \mathrm{~cm}^{-1}$, a feature not present in noncrystalline $\mathrm{SiO}_{2}$. This has been assigned in Ref. 1 to a stretching vibration associated with a terminal $\mathrm{Si}-\mathrm{O}$ bond that is a product of the $\mathrm{SiO}_{2}$ network disruption that occurs upon forming a pseudobinary alloy with $\mathrm{ZrO}_{2} \cdot{ }^{3,5}$ The feature is specifically associated with a terminal $\mathrm{O}$ atom covalently bonded to a network $\mathrm{Si}$, and making a considerably more ionic bond with a $\mathrm{Zr}^{4+}$ ion (see Fig. 1 of Ref. 2). This feature is then expected to grow as the $\mathrm{ZrO}_{2}$ content increases, and this is clearly evident in Figs. 1(a) and 1(b). Figure 12(a) is a plot of the absorption in the
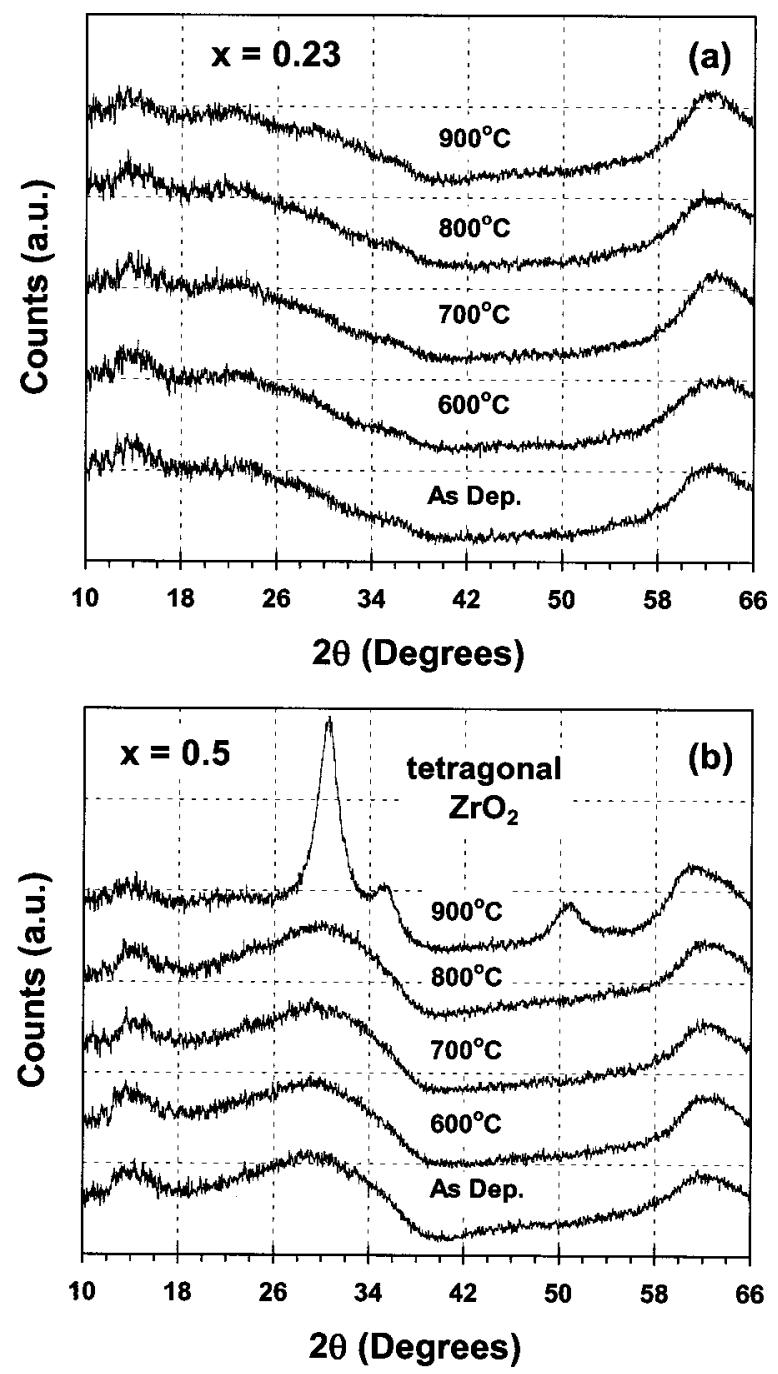

FIG. 10. X-ray diffraction results for two $\mathrm{Zr}$ silicate alloys: (a) 0.23 and (b) 0.50 , as a function of temperature.

spectral region of the asymmetric and symmetric modes between 700 and $1400 \mathrm{~cm}^{-1}$. The increase in the number of terminal $\mathrm{Si}-\mathrm{O}$ bonds has two effects on these spectra, which are amplified in the derivative spectrum in Fig 12(b). As $x$ is increased the leading edge and trailing edge features of the symmetric stretching mode increase in relative strength to the central peak. The leading edge feature has been assigned to a fourfold coordination symmetry determined out-ofphase oxygen atom motions about a common $\mathrm{Si}^{9}{ }^{9}$ and the peak at $\sim 1060 \mathrm{~cm}^{-1}$ is assigned to the in-phase oxygen atom motion. As the number of dangling $\mathrm{Si}-\mathrm{O}$ bonds is increased these symmetry-determined motions lose the significance they have for a tetrahedral arrangement of twofoldcoordinated oxygen atoms and the high frequency shoulder and central peak merge as in $\mathrm{Si}$ suboxides, $\mathrm{SiO}_{x}, x<2 .{ }^{10}$ The low wave number shoulder is a manifestation of bond breaking, and the creation of terminal $\mathrm{Si}-\mathrm{O}$ groups ${ }^{1,2}$ and has its own spectroscopic signature. The spectrum for $x=0.5$ in Fig. 2 (c) is for a chemically ordered alloy in which the $\mathrm{SiO}_{2}$ network has been completely disrupted. It is comprised of $\mathrm{SiO}_{4}^{4-}$ ions and $\mathrm{Zr}^{4+}$ ions, where the oxygen atoms have a 
(a)

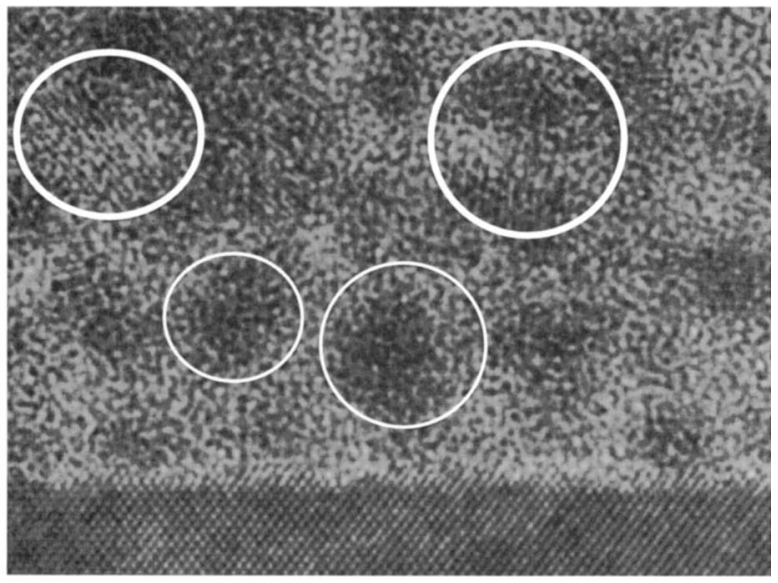

(b)

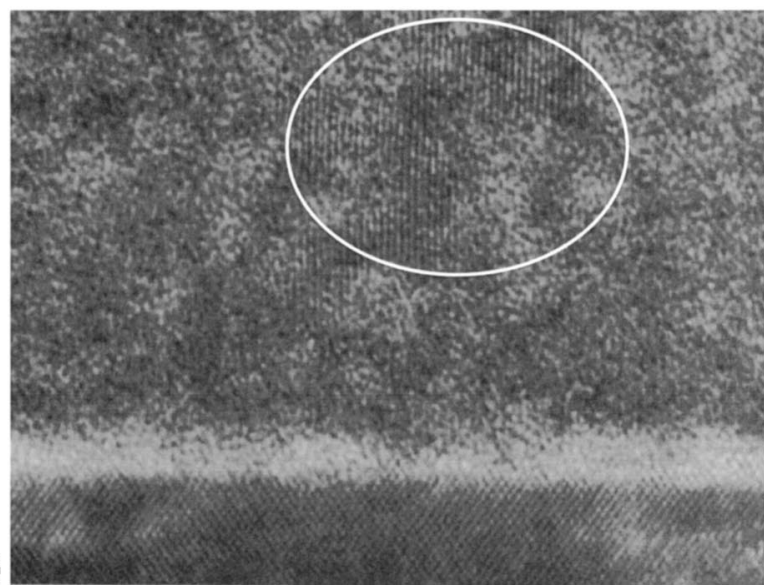

FIG. 11. HRTEM images for two Zr silicate alloys samples after annealing at $900{ }^{\circ} \mathrm{C}$ : (a) $x \sim 0.25$ and (b) $x \sim 0.50$. The length scale is established by the Si lattice plane spacing of $\sim 0.33 \mathrm{~nm}$ in the lower portion of each micrograph.

threefold coordination. ${ }^{2}$ For the as-deposited spectra, and the samples annealed below $900{ }^{\circ} \mathrm{C}$, the first broad feature centered at about $900 \mathrm{~cm}^{-1}$ is the signature of the $\mathrm{SiO}_{4}^{4-}$ ion. This assignment is supported by the spectrum in Fig. 2 for a $\mathrm{ZrO}_{2}$-rich alloy, with $x=0.61$. The second broad feature in Fig. 2, centered at approximately $410 \mathrm{~cm}^{-1}$, is due to $\mathrm{Zr}-\mathrm{O}$ vibrations as an amorphous structure. This assignment is supported by the absorption spectrum for a crystalline sample of $\mathrm{ZrO}_{2}$ in Fig. 4, which shows considerably sharper features in the same spectral regime centered at about $400 \mathrm{~cm}^{-1}$.

The four sets of spectra in Figs. 2(a), 2(b), and 2(c) and Fig. 3 showed marked changes after annealing to $900{ }^{\circ} \mathrm{C}$. These are consistent with a chemical phase separation of the homogeneous alloy, or solid solution, into its two chemical constituents, $\mathrm{SiO}_{2}$ and $\mathrm{ZrO}_{2}$. In particular, the marked decrease in Figs. 2(a) and 2(b) of the $970 \mathrm{~cm}^{-1} \mathrm{Si}-\mathrm{O}$ terminal group vibration is consistent with this bonding being restricted to the internal phase boundaries between the $\mathrm{SiO}_{2}$ and $\mathrm{ZrO}_{2}$. After the $900{ }^{\circ} \mathrm{C}$ anneal, the spectral features below about $500 \mathrm{~cm}^{-1}$ in the $x=0.61$ spectrum in Fig. 3 are quantitatively different that those in the crystalline spectrum of $\mathrm{ZrO}_{2}$ in Fig. 3. This is assigned to the differences in crys-
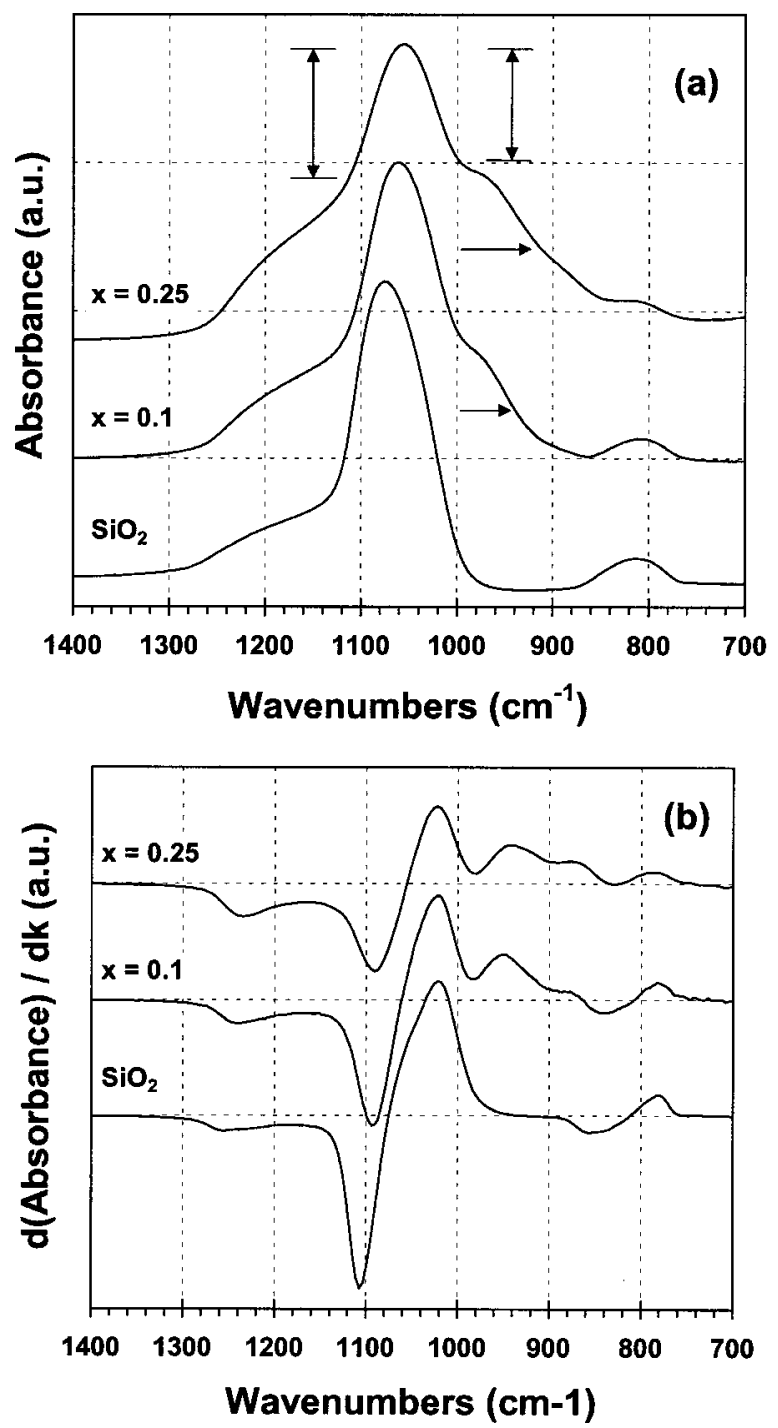

FIG. 12. FTIR spectra and differentiated FTIR spectra for as-deposited Zr silicate alloys: (a) $x=0.25$ and (b) $x=0.50$.

talline structure, and/or crystallite size. The similarity between the leading edge of this band in Figs. 1(c) and 3, after the $900{ }^{\circ} \mathrm{C}$ anneal suggests crystallinity in the $x=0.5$ sample as well, but this is not definitive based solely on FTIR, and will be resolved in the other measurements discussed below.

Figures 4(a) and 4(b) present O $1 s$ XPS core level spectra, and differentiated XPS core level spectra for asdeposited $\mathrm{Zr}$ silicate alloys. The asymmetric character of the features, that is most pronounced in the $x=0.23$ and 0.76 alloys, is a manifestation of different bonding coordinations for oxygen atoms and has been addressed in detail in Ref. 2 . Figures 5(a) and 5(b) are XPS spectra for: (a) Zr 3d core states, and (b) Si $2 p$ states. Since these spectra do not exhibit any marked asymmetries, differentiated spectra are not shown. The spectra in Figs. 6(a) and 6(b) are the XPS O $1 s$ core level spectra, and the corresponding first-derivative spectra, respectively, for compositions of $x=0.35,0.45$, and 0.60 after annealing at $900{ }^{\circ} \mathrm{C}$. These spectra have a concentration independent doublet character that is clearly evident 
in the differentiated spectra, and also present in the undifferentiated spectra for the $x=0.45$ and 0.60 alloys. Based on comparisons with the $\mathrm{O} 1 s$ core level spectra in Fig. 4(a), the two alloy concentration independent features in these spectra are assigned to $\mathrm{SiO}_{2}$ - and $\mathrm{ZrO}_{2}$-rich phases. There is no aspect of these spectra that discriminates between crystalline and noncrystalline $\mathrm{ZrO}_{2}$, or between $\mathrm{ZrO}_{2}$ with different degrees of crystallinity, e.g., nanocrystallites $<5 \mathrm{~nm}$, and larger crystallites or grains $>10 \mathrm{~nm}$. However, the additional and/or confirmatory information relative to chemical phase separation that is evident in the numerically differentiated spectra in Fig. 6(b) is obvious.

Figures 7(a) and 8(b) present oxygen atom $K_{1}$ edge XAS spectra for three $\mathrm{Zr}$ silicate alloys, $x=0.35,0.45$, and 0.6 , as deposited in (a) and after a $900{ }^{\circ} \mathrm{C}$ rapid thermal anneal in (b). Oxygen atom $K_{1}$ edge spectra have been discussed in detail for $\mathrm{ZrO}_{2}$, the alloys in this article, as well as other transition metal oxides, e.g., $\mathrm{HfO}_{2}$ and $\mathrm{Y}_{2} \mathrm{O}_{3}$, and transition metal silicates and aluminates, e.g., $\mathrm{HfO}_{2}-\mathrm{Al}_{2} \mathrm{O}_{3}$ and $\mathrm{HfO}_{2}-\mathrm{SiO}_{2}$ alloys. ${ }^{7}$ The changes that occur after the $900{ }^{\circ} \mathrm{C}$ anneal are significantly stronger in the $x=0.60$ alloy, and these will be shown to be a result of chemical phase separation that is accompanied by crystallization. The $4 d^{*}$ feature is much sharper, and the structure in the $5 s^{*}$ feature is essentially the same as that in the oxygen atom $K_{1}$ edge of crystalline $\mathrm{ZrO}_{2}$ as presented in Ref. 7 .

The emergence of second neighbor $\mathrm{Zr}-\mathrm{Zr}$ features in Figs. 8(a) and 8(b) after the $900{ }^{\circ} \mathrm{C}$ anneal is clear evidence of a transition in which there is order on a crystalline scale. The differences between the Fourier transform spectra in Figs. 8(a) and 8(b) after this anneal are consistent with increased crystalline order in the $x=0.55$ alloy as compared to the 0.25 alloy. This difference in crystalline order is clearly evident in the XRD results presented in Figs. 10(a) and 10 (b). After annealing at $900{ }^{\circ} \mathrm{C}$, there are clearly crystalline features in the XRD spectrum of a sample with $x=0.5$, whereas, there are no distinct crystalline features in the $x$ $=0.23$ feature after this anneal. This suggests larger, more well organized crystallinity in the 0.55 sample, consistent with the relative size of the $\mathrm{Zr}-\mathrm{Zr}$ features in the EXAFS analysis after the $900{ }^{\circ} \mathrm{C}$ anneal. This explanation is supported by the HRTEM images in Figs. 11(a) and 11(b), which are for $x \sim 0.25$ and $\sim 0.5$ alloys after a $900{ }^{\circ} \mathrm{C}$ anneal. The contrast in Fig. 11(a) is consistent with chemical phase separation into $\mathrm{ZrO}_{2}$ - and $\mathrm{SiO}_{2}$-rich regions, with the darker regions being $\mathrm{ZrO}_{2}$ rich. There is some suggestion of ordering in the regions highlighted by the thicker white rings; however, these are qualitatively different than the lattice planes clearly evident in Fig. 11(b). Combined with the EXAFS results in Figs. 8(a) and 8(b), the HRTEM images suggest that there are crystallites on a scale $\sim 10 \mathrm{~nm}$ in the $x$ $\sim 0.5$ alloy, and that any crystalline order is on a much smaller scale, $<5 \mathrm{~nm}$, in the $x \sim 0.25$ alloy. This interpretation is consistent with a concentration gradient of $\mathrm{Zr}$ in the alloy films. The alloy closer the substrate has less $\mathrm{ZrO}_{2}$, and therefore shows a smaller degree of crystalline organization after the $900^{\circ} \mathrm{C}$ anneal.
Finally, the spectra in Figs. 9(a) and 9(b) are consistent with a chemical phase separation that includes a $\mathrm{ZrO}_{2}$-rich phase after the $900{ }^{\circ} \mathrm{C}$ anneal.

The experimental data presented in this article clearly identify different types of phase separation. For alloy compositions greater than $x \sim 0.5$, chemical phase separation after an anneal at $900{ }^{\circ} \mathrm{C}$ in a chemically inert environment such as $\mathrm{Ar}$ is accompanied by crystallization on a scale that is readily detectable by XRD [Fig. 10(b)], and is also clearly evident in HRTEM images [Fig. 11(b)] where the crystallite, or grain size, is $\sim 10 \mathrm{~nm}$. This conclusion is supported by the relative strength of the $\mathrm{Zr}$ atom second neighbor features in the radial distribution function derived from EXAFS [Fig. 8(b)]. The crystallinity of the separated $\mathrm{ZrO}_{2}$-rich phase is also evident in the XAS oxygen $K_{1}$ edge spectra in Fig. 7(b).

Chemical phase separation is also evident for all compositions by the other spectroscopic approaches used, for example, FTIR, XPS, and differential XPS; however, these techniques cannot give additional information relative to crystallinity For example, the HRTEM and EXAFS spectra indicate evidence for crystallinity but on a scale of $\sim 3 \mathrm{~nm}$, which is too small to give features that can be detected by conventional XRD.

The combination of spectroscopic approaches presented in this article provide a tool box that can be applied to other pseudobinary alloys as well. For example, derivative XPS applied to $\mathrm{O} 1 s$ spectra before and after annealing cycles provides a sensitive technique for detecting separation, and EXAFS measurements provide a sensitive technique for establishing differences in the dimensions of the resulting crystallites. The combination of these two spectra with HRTEM provides a way of determining the size of the crystallites in the range of 3-10 nm. The results of this study indicate that chemical phase separation of $\mathrm{Zr}$ silicate alloys generally yields in a $\mathrm{ZrO}_{2}$ cyrstalline phase, where the size of the crystallites is a function of the alloy composition. For example, for an alloy composition of $\sim 0.25$, the crystallites are $\sim 3 \mathrm{~nm}$, whereas for an alloy composition of $\sim 0.5$ they increase to about $10 \mathrm{~nm}$.

In conclusion, combining derivative XPS with EXAFS RDFs provides an unambiguous and effective way to study chemical phase separation with different degrees of crystallization. This is of importance for semiconductor device processing since chemical phase separation in $\mathrm{SiO}_{2}$-rich $\mathrm{Zr}$ and $\mathrm{Hf}$ silicates reduces gate dielectric capacitance, and therefore can adversely affect current drive in FETs. ${ }^{13}$

\section{ACKNOWLEDGMENTS}

The authors wish to acknowledge support for this research from Office of Naval Research (ONR), Air Force Office of Scientific Research (AFSOR), Semiconductor Research Corporation (SRC), and the i-SEMATECH/SRC Front End Processes (FEP) Center. The assistance of Professor Dale Sayers of N.C. State University in the EXAFS measurements and their interpretation is gratefully acknowledged, as is the assistance of Professor Harald Ade of NC State University in the XAS measurements and their interpretation. 
${ }^{1}$ G. B. Rayner, Jr., R. Therrien, and G. Lucovsky, Mater. Res. Soc. Symp. Proc. 611, c13.1 (2001)

${ }^{2}$ G. B. Rayner, Jr., D. Kang, Y. Zhang, and G. Lucovsky, J. Vac. Sci. Technol. B 20, 1748 (2002).

${ }^{3}$ J. P. Maria, D. Wicaksana, A. I. Kingon, B. Busch, H. Schulte, E. Garfunkel, and T. Gustafsson, J. Appl. Phys. 90, 3476 (2001).

${ }^{4}$ G. D. Wilk, R. M. Wallace, and J. M. Anthony, J. Appl. Phys. 87, 484 (2001).

${ }^{5}$ G. D. Wilk, R. W. Wallace, and J. M. Anthony, J. Appl. Phys. 89, 5243 (2001).

${ }^{6}$ G. Lucovsky, G. B. Rayner, Jr., D. Kang, G. Appel, R. S. Johnson, Y. Zhang, D. E. Sayers, H. Ade, and J. L. Whitten, Appl. Phys. Lett. 79, 1775 (2001)

${ }^{7}$ G. Lucovsky, Y. Zhang, G. B. Rayner, Jr., G. Appel, H. Ade, and J. L.
Whitten, J. Vac. Sci. Technol. B 20, 1739 (2002).

${ }^{8}$ F. L. Galeener and G. Lucovsky, Phys. Rev. Lett. 37, 1474 (1976).

${ }^{9}$ G. Lucovsky, C. K. Wong, and W. B. Pollard, J. Non-Cryst. Solids 59 \& 60, 839 (1983)

${ }^{10}$ P. G. Pai, S. S. Chao, Y. Takagi, and G. Lucovsky, J. Vac. Sci. Technol. A 4, 689 (1986).

${ }^{11}$ X-Ray Absorption: Principles, Applications, Techniques of EXAFS, SEXAFS and XANES, edited by D. C. Koningsberger and R. Prins (Wiley, New York, 1988).

${ }^{12}$ P. A. Cox, Transition Metal Oxides (Oxford Science, Oxford, 1992), Chap. 2, and references therein.

${ }^{13}$ G. Lucovsky, Extended Abstracts of 8th Workshop on Formation, Characterization and Reliability of Ultrathin Silicon Oxides, Atagawa, Japan, 2003. 